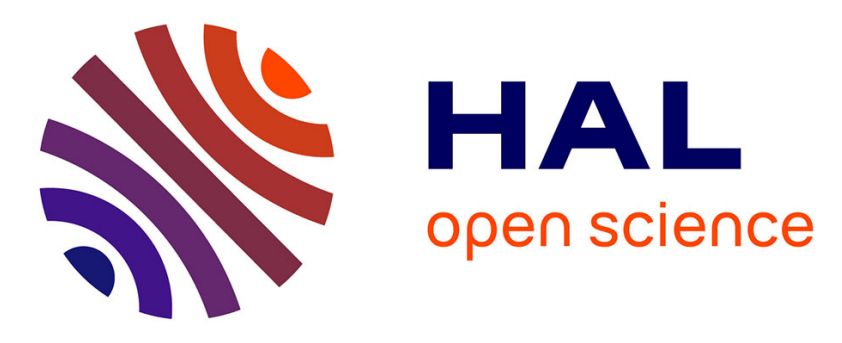

\title{
SiGe derivatization by spontaneous reduction of aryl diazonium salts
}

Aurélie Girard, Florence Geneste, Nathalie . Coulon, Christophe Cardinaud, Tayeb Mohammed-Brahim

\section{- To cite this version:}

Aurélie Girard, Florence Geneste, Nathalie . Coulon, Christophe Cardinaud, Tayeb MohammedBrahim. SiGe derivatization by spontaneous reduction of aryl diazonium salts. Applied Surface Science, 2013, 282, pp.146-155. 10.1016/j.apsusc.2013.05.091 . hal-00860238

\section{HAL Id: hal-00860238}

\section{https://hal-univ-rennes1.archives-ouvertes.fr/hal-00860238}

Submitted on 10 Sep 2013

HAL is a multi-disciplinary open access archive for the deposit and dissemination of scientific research documents, whether they are published or not. The documents may come from teaching and research institutions in France or abroad, or from public or private research centers.
L'archive ouverte pluridisciplinaire HAL, est destinée au dépôt et à la diffusion de documents scientifiques de niveau recherche, publiés ou non, émanant des établissements d'enseignement et de recherche français ou étrangers, des laboratoires publics ou privés. 


\title{
SiGe derivatization by spontaneous reduction of aryl diazonium salts
}

\author{
A. Girard ${ }^{\mathrm{a}}$, F. Geneste ${ }^{\mathrm{b}}$, N. Coulon ${ }^{\mathrm{a}}$, C. Cardinaud ${ }^{\mathrm{c}}$, T. Mohammed-Brahim ${ }^{\mathrm{a}}$ \\ ${ }^{a}$ UMR-CNRS 6164, IETR, Université de Rennes 1, Campus de Beaulieu, 35042 Rennes cedex, France \\ ${ }^{b}$ UMR-CNRS 6226, Institut des Sciences Chimiques de Rennes, Equipe MaCSE, Université de Rennes 1, Campus de Beaulieu, 35042 Rennes \\ cedex, France \\ ${ }^{c}$ UMR-CNRS 6502 Institut des matériaux Jean Rouxel Université de Nantes, 2 rue de la Houssinière, BP32229, F-44322 Nantes cedex3, France
}

\begin{abstract}
Germanium semiconductors have interesting properties for FET-based biosensor applications since they possess high surface roughness allowing the immobilization of a high amount of receptors on a small surface area. Since SiGe combined low cost of Si and intrinsic properties of $\mathrm{Ge}$ with high mobility carriers, we focused the study on this particularly interesting material. The comparison of the efficiency of a functionalization process involving the spontaneous reduction of diazonium salts is studied on $\mathrm{Si}(100), \mathrm{SiGe}$ and Ge semiconductors. XPS analysis of the functionalized surfaces reveals the presence of a covalent grafted layer on all the substrates that was confirmed by AFM. Interestingly, the modified Ge derivatives have still higher surface roughness after derivatization. To support the estimated thickness by XPS, a step measurement of the organic layers is done by AFM or by profilometer technique after a $\mathrm{O}_{2}$ plasma etching of the functionalized layer. This original method is well-adapted to measure the thickness of thin organic films on rough substrates such as germanium. The analyses show a higher chemical grafting on SiGe substrates compared with Si and Ge semiconductors.
\end{abstract}

Keywords: Germanium, diazonium salts, derivatization, film thickness, plasma etching, semiconductors

\section{Introduction}

Microelectronic devices like field effect transistors are of considerable interest for chemical and biological detection due to their miniaturization and low cost production $[1,2,3,4]$. The selectivity of this type of sensor is directly linked to the sensitive surface that interacts with the analyte or the biomolecular material. Indeed, the introduction of a selective layer to semiconductor based transducers, which are able to evaluate the electrical changes induced by target species binds to the immobilized recognition receptors, makes possible the electrical detection of species of interest. Due to the importance of this sensitive layer, many efforts have been made to achieve stable and well-controlled functionalization of semiconductors.

One of the most studied materials is silicon-composed surfaces. Indeed, they are used in many well-known microfabrication methods and their deposition processes are well-controlled. Among all the procedures that have been developed to functionalize silicon surfaces [5, 6, 7], electrografting of arenediazonium salts is a well-known method to prepare phenyl layers on H-terminated planar Si surfaces [8, 9]. Advantageously, this efficient and fast grafting process performed in reduction is compatible with easily oxidative substrates and leads to a strong covalent bond between a wide range of functionalized molecules and surfaces. The reduction of diazonium salts can be performed electrochemically, in the presence of exogenous reductant species [10,11] or even spontaneously [12]. Monolayers

Email addresses: girard aurelie@univ-rennes1.fr (A. Girard), geneste.florence@univ-rennes1.fr (F. Geneste) 
or thin films are usually obtained in well-controlled conditions [13,14, 15, 16, 17]. The aryl diazonium salts can be prepared in situ from the aniline derivative during the grafting process, simplifying the synthesis of the starting material. Thus, the immobilized aryl compound can serve as anchoring sites for molecules like biological species or may be terminated with a variety of end groups that respond to different biological or chemical stimuli $[18,19,20,21]$. Spontaneous grafting from aryl diazonium salts is highly advantageous, because it is easy to set up and the functionalization occurs only on conducting area. Therefore, the species to detect are localized on the sensitive part of the sensor, facilitating the processing for analysis with microelectronic devices [22].

Another important parameter in the field of sensing is the surface area of the sensitive layer; the higher sensitive surface area we have, the higher density of binding sites we get. Since, the sensitive surface is limited by the sensor design, a good way to improve the surface area would be to increase its roughness. An interesting semiconductor that has not been fully exploited for sensor applications is germanium derivatives. Indeed, as silicon surfaces, it has a wellcontrolled conductivity (doping process), the crystal growth technique is well-established and Ge-based materials are compatible with Si technology. The absence of a stable germanium oxide, previously seen as a major drawback for germanium device fabrication, can now be circumvented using new insulating materials such as high-k dielectrics [23]. Thus, the very high lattice mobility of both electrons and holes in the germanium substrate, providing higher drive current and smaller gate delay for transistor devices, in addition with a high roughness of its surface (fifty times higher than those of silicon) made it a material of choice for sensing applications. Although many methods have been used to functionalize Ge surfaces and especially nanowires [24, 25, 26], only a few and recent articles deal with the reduction of diazonium salts $[27,28]$. Spontaneous grafting has been reported for the first time on germanium nanowires [27]. The reaction was reported to be slow at room temperature, but proceeded efficiently with moderate heating. Bulk Ge surfaces have presented better reactivity, since surface modification occurred at room temperature [28]. In these conditions, a mechanism has been proposed involving the spontaneous reduction of diazonium salts by $\mathrm{Ge}$, producing aryl radicals that graft on the surface.

$\mathrm{SiGe}$ was chosen in this work since it possesses the intrinsic properties of Ge (high surface roughness, high mobility of both electrons and holes, high frequency performance and low band gap), it is composed of a thin Ge layer, reducing the problems of cost and limited availability of Ge and its use in microelectronic process is even closer to that of silicon than Ge. We report the derivatization of SiGe by spontaneous grafting of diazonium salts. A comparison of the efficiency of the grafting process on $\mathrm{Si}(100)$, SiGe and Ge semiconductors was performed by using XPS and AFM analyses. The efficiency of the grafting process depends on the nature of the semiconductor, as evidenced by film thickness measurements. An answer to the difference of activity is proposed from this study. Another outcome of this analysis is the possibility to measure the organic layer thickness on a wide range of materials with various surface roughnesses.

\section{Chemicals}

\subsection{Reagents}

4-carboxymethyl-benzenediazonium salts were prepared according to literature and stored under argon in a freezer [29]. All solvents were HPLC grade. Ultrapure water (18.2 M $\omega$, Millipore Simplicity) was used for the grafting procedure.

\subsection{Preparation of the modified surfaces}

All manipulations were carried out under argon on a Schlenk line with standard airless techniques. A $2 \%$ hydrofluoric acid solution was cannulated into a reactor cell containing the surfaces under argon to remove the native Ge and Si oxide. After 2 min of immersion, the HF solution was eliminated and the surfaces were washed with ultrapure and deoxygenated water. A solution containing $100 \mathrm{mg}$ of 4-carboxymethyl-benzenediazonium salts in $50 \mathrm{~mL}$ of anhydrous deoxygenated acetonitrile was cannulated into the reactor cell. After $1 \mathrm{~h}$, the surfaces were washed in six successive baths of acetonitrile of 10 min each. It is worth noting that the grafted layer was still observed in XPS when the samples were sonicated 3 times in acetonitrile for $5 \mathrm{~min}$. Before analyses, the samples were stored under argon in a fridge. 


\begin{tabular}{lclccc}
\hline Layer types & $\mathrm{T}^{\circ} \mathrm{C}$ & $\begin{array}{l}\mathrm{SiH}_{4} \\
(\mathrm{sccm})\end{array}$ & $\begin{array}{l}\mathrm{GeH}_{4} \\
(\mathrm{sccm})\end{array}$ & $\begin{array}{l}\mathrm{B}_{2} \mathrm{H}_{6} \\
(\mathrm{sccm})\end{array}$ & Postbake $\mathrm{T}^{\circ} \mathrm{C}$ \\
\hline Heavily P-type polycrystalline SiGe & 500 & 50 & 50 & 40 & 600 \\
Heavily P-type polycrystalline Ge & 500 & - & 50 & 40 & 600 \\
\hline
\end{tabular}

Table 1. LPCVD parameters.

\subsection{Substrates}

In this work, two types of materials composed of germanium and silicon were studied. As a reference, we add a silicon monocristal wafer, oriented 100 , which is a microelectronic grade material (high purity) with well-known properties. This phosphorous-doped $(1-10 \mathrm{ohm} / \mathrm{cm}) \mathrm{n}$-type Si has a thickness of $280 \mu \mathrm{m}$. It was purchased from B T Electronics.

The materials composed with germanium are deposited in the IETR laboratory on glass substrates. First, on this Corning Eagle glass substrates, a $250 \mathrm{~nm}$ buffer oxide layer was deposited by APCVD (Atmospheric Pressure Chemical Vapor Deposition) technique at the temperature of $420^{\circ} \mathrm{C}$ with $\mathrm{SiH}_{4}-\mathrm{N}_{2}-\mathrm{O}_{2}$ gas mixture. This oxide layer acts as a diffusion barrier in order to avoid the possible contamination of the layers by impurities in the substrate.

Before $\mathrm{Ge}$ or SiGe deposition $(400 \mathrm{~nm})$, we made a thin layer of $\mathrm{Si}(10 \mathrm{~nm})$ which is necessary for adhesion. Then, the films composed with germanium were amorphously deposited at $500^{\circ} \mathrm{C}$ with a total deposition pressure of $90 \mathrm{~Pa}$ using a hot wall LPCVD (Low Pressure Chemical Vapor Deposition) reactor. Boron (1000 ppm $\mathrm{B}_{2} \mathrm{H}_{6}$ diluted in hydrogen) in situ doped germanium and polysilicon-germanium films are deposited with the same conditions using a mixture of silane and germane diluted in hydrogen $\left(20 \% \mathrm{GeH}_{4}, \mathrm{H}_{2}\right)$ as precursor gas and diborane as a doping gas. A $50 \mathrm{sccm}$ flow rate of pure silane, $\mathrm{SiH}_{4}$, is injected in the front of the reactor with a $50 \mathrm{sccm}$ flow rate of the mixture of $20 \%$ of germane.

Doping concentration measured by secondary mass spectroscopy (SIMS) is $5.10^{19}$ atom/ $\mathrm{cm}^{3}$. After depositing each layer, a solid phase crystallization (SPC) process for $12 \mathrm{~h}$ at $600^{\circ} \mathrm{C}$ under vacuum was carried out. All the conditions are summarized in Table 1.

The functionalized surfaces were analyzed using Atomic Force Microscopy (AFM), Scanning Electron Microscopy (SEM), profilometry and X-Ray Photoelectron Spectroscopy (XPS). The average film thicknesses obtained from AFM profiling and profilometer scans were calculated from ten line measurements.

\subsection{Instrumentation}

\subsection{1. $A F M$}

The Atomic Force Microscopy (AFM) images were obtained in air, operating in tapping mode, using a Veeco AFM diCaliber High Value Scanning Probe Microscope with a standard antimony doped silicon tip which is a cantilever with a resonant frequency of $300 \mathrm{kHz}$. All the images were recorded with a 512 points per line resolution at a scan rate of $1 \mathrm{~Hz}$. Tapping mode was used to determine all the changes at the surface of our substrates caused by the grafting modification.

\subsection{SEM}

The SEM micrographs were obtained with a Jeol 6301F (9 kV) microscope. A scanning electron microscopy may be used not only to observe a surface image but also to provide a fine electron beam for charging an isolator surface simultaneously [30, 31].

\subsubsection{Contact profilometry}

The film thickness was measured by means of a stylus profilometer (KLA Tencor P6 Profiler), equipped with a diamond stylus (radius $2 \mu \mathrm{m}$ ), by applying a force of $2 \mathrm{mg}$. 


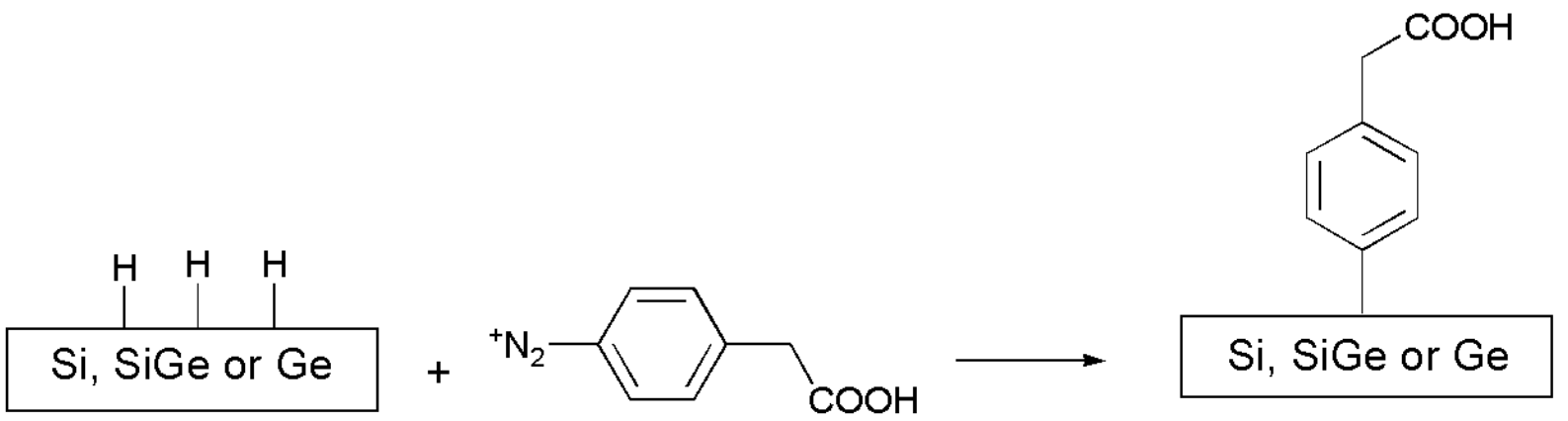

Figure 1. Derivatization of microconductors surfaces by spontaneous reduction of diazonium salts.

\subsubsection{XPS}

X-Ray photoelectron spectroscopy (XPS) has been carried out with a Kratos Axis Ultra HSA spectrometer using a monochromatic $\mathrm{Al} \mathrm{K} \alpha$ excitation $(1486.6 \mathrm{eV})$, with magnetic confinement charge neutralization, which is very effective in minimizing both uniform charging and differential charging on this large-band-gap semiconductor. The hybrid lens magnification mode was used with the slot aperture resulting in an analyzed area of 700 per $300 \mu \mathrm{m}^{2}$. Charge stabilization was achieved by using the Kratos Axis device. The pass energy was set at $20 \mathrm{eV}$ for the detailed scans. In these conditions, the energy resolution gives a full width at half maximum (FWHM) of the $\mathrm{Ag} 3 \mathrm{~d} 5 / 2$ peak of about $0.55 \mathrm{eV}$. Wide scans were recorded with a step size of $0.5 \mathrm{eV}$ and a pass energy of $80 \mathrm{eV}$, for narrow scans the corresponding parameters were 0.1 and $20 \mathrm{eV}$, respectively. The photoelectron take-off angle was $90^{\circ}$ with respect to the sample plane, which provides an integrated sampling depth of approximately $15 \mathrm{~nm}$ for XPS.

Normal XPS analysis provides information on the nature of the chemical bonds of samples through the determination of core-level binding energies. The data were collected at room temperature, and the operating pressure in the analysis chamber was always below $10^{-9}$ Torr. Peak positions were referenced to aliphatic carbon $(\mathrm{C}-\mathrm{C} / \mathrm{C}-\mathrm{H} 1 \mathrm{~s}$ peak) at $285.0 \mathrm{eV}[8,32,33]$. Data treatment and peak fitting procedures were performed using Casa XPS software (version 2.3.16) and Kratos data base of relative sensitivity factors. Deconvolution of spectra into Gaussian-Lorentzian peaks $(\mathrm{G} / \mathrm{L}=30)$, was also done using Casa XPS software, with peak area and width as free fitting parameters. A Shirley function was used to model the background. Peak assignments were made based on comparing the binding energies with reports in the literature for similar molecular species.

\section{Results}

\subsection{Grafting from diazonium salt solution}

A pretreatment of $\mathrm{Si}$ and Ge surfaces in $2 \% \mathrm{HF}$ was first necessary to achieve hydride termination. After washing, the surfaces were immersed into a solution of 4-carboxymethyl-benzenediazonium salts in acetonitrile for $1 \mathrm{~h}$, leading to spontaneous grafting of the aryl species to silicon and germanium surfaces (Figure 1) [34].

4-carboxymethyl-benzenediazonium salts were chosen since their carboxylic acid function can serve as an anchoring point for other compounds. A preliminary study on silicon surfaces with AFM analyses and SEM images led us to consider $1 \mathrm{~h}$ of immersion for the grafting process as the best conditions to obtain a uniform film. Indeed, beyond $2 \mathrm{~h}$, clusters appear on the surfaces and indicate a non-uniformity of the grafted film.

\subsection{Roughness study}

Surface roughness is a current factor to check the presence of a molecular layer on the surface. Indeed, the organic film growth can modify the substrate roughness. The RMS roughness of unmodified and modified silicon, silicongermanium and germanium surfaces was obtained from a measurement on 50 by $50 \mu \mathrm{m}$ images, in tapping mode AFM (Table 2).

The increase of the roughness was observed on all the substrates, showing the effectiveness of the grafting process. Further characterizations were then performed by XPS, AFM and SEM. 


\begin{tabular}{lcl}
\hline Substrates & Roughness before & Roughness after \\
\hline Silicon (100) & $0.3 \mathrm{~nm}$ & $1.1 \mathrm{~nm}$ \\
Heavily P-type polycrystalline SiGe & $15.0 \mathrm{~nm}$ & $17.6 \mathrm{~nm}$ \\
Heavily P-type polycrystalline Ge & $14.6 \mathrm{~nm}$ & $24.1 \mathrm{~nm}$ \\
\hline
\end{tabular}

Table 2. RMS roughness of samples before and after grafting.

\begin{tabular}{lc}
\hline Substrates & Thickness of grafted diazonium layer \\
\hline Silicon (100) & $2.6 \mathrm{~nm}$ \\
Heavily P-type polycrystalline SiGe & $4.2 \mathrm{~nm}$ \\
Heavily P-type polycrystalline Ge & $3.2 \mathrm{~nm}$ \\
\hline
\end{tabular}

Table 3. Thickness of the grafted layer deduced from the attenuation of the signal.

\subsection{XPS characterization}

XPS measurements performed on the materials after immersion in the diazonium salt solutions reveal clearly that grafting occurs: all the spectra show photoelectron peaks characteristic of the diazonium salt used. Figure 2 shows an example of wide-scan XPS for the unmodified and modified surface.

A C1s peak was observed in the spectra of $\mathrm{Si}, \mathrm{SiGe}$ and Ge surfaces. This may be due to pollution by oil vapor pumping LPCVD system or atmospheric contamination. The presence of oxygen was also observed, probably due to the reoxidation of the substrate before XPS analysis.

The presence of grafted aryl species was evidenced with XPS by analyzing C1s, Si2p and Ge3d core level. Figure 3 shows the XPS spectra of C1s (Figure 3a), Si2p (Figure 3b) and Ge3d (Figure 3c) core levels for SiGe samples with and without functionalization.

Grafting clearly leads to an increase of the $\mathrm{C} 1 \mathrm{~s}$ and $\mathrm{O} 1 \mathrm{~s}$ peaks centered at 285.0 and $532.4 \mathrm{eV}$ respectively. We notice that photoelectron peaks characteristic of the substrates ( $\mathrm{Si} 2 \mathrm{p}, \mathrm{Ge} 3 \mathrm{~d}$ ) are attenuated but still visible after the organic layer has been grafted. This result indicates either the formation of a organic layer onto the substrate with a thickness thinner than the depth analyzed by the XPS technique. This is consistent with the calculation of the grafted layer thickness (Table 3 ) which is less than the depth of analysis. In the case of a polycrystalline silicon-germanium and germanium layer, the thickness of the grafted layer is about $4.2 \mathrm{~nm}$ and $3.2 \mathrm{~nm}$, respectively, against $2.6 \mathrm{~nm}$ for monocrystalline silicon (100) (Table 3).

The decrease of Ge3d peak indicates that Ge is depleted near at the surface and a Si-rich layer is generated. The depletion of Ge near the surface layer is caused by surface Ge dissolving into the HF-acid solutions. The phenomenon of dissolution of $\mathrm{Ge}$ atoms during the $\mathrm{HF}$ acid treatment and the depletion of $\mathrm{Ge}$ layers on the surface has already been demonstrated [27, 39].

The high resolution C1s spectra of the polycrystalline silicon-germanium and the modified sample are shown in Figure 4. Deconvolution of spectra and peak assignments are made taking into account the data of literature for similar molecular species (Table 4). C1s spectra of the polycrystalline silicon-germanium (Figure 4a) can be decomposed into three features: one located at $284.8 \mathrm{eV}$ assigned to $\mathrm{C}-\mathrm{C}$ bonds, one at $286.7 \mathrm{eV}$ assigned to $\mathrm{C}-\mathrm{O}$ bonds and the last at $288.7 \mathrm{eV}$ assigned to $\mathrm{C}=\mathrm{O}$ bonds. With respect to the functionalized surface, the $\mathrm{C}$ peak at $284.8 \mathrm{eV}$ characterized by $\mathrm{C}-\mathrm{C}$ bonds increases significantly as a phenyl layer was grafted on the surface (Figure $4 \mathrm{~b}$ ). The intensity of the peak at $286.7 \mathrm{eV}$ which is obviously attributed to the $\mathrm{C}-\mathrm{O}$ bonds increased after grafting. Besides, we observe the increase of the peak located at $289.0 \mathrm{eV}$. This can be attributed to the functional group $\mathrm{COOH}$ [40, 41]. Interestingly, a new carbon peak appears at $283.1 \mathrm{eV}$ in the spectrum of the modified sample which corresponds to a carbide link [42]. This small C1s signal is, however, really important as it was interpreted for many times in the literature as an evidence of the covalent metal-carbon bond between the metal surface and phenyl group grafted through the diazonium route $[8,43]$. The peak found at around $283 \mathrm{eV}$ was reported for the first time to be a direct proof for the existence of a covalent bond between an aryl group and the iron substrate [44].

The presence of carbide covalent bonds is also highlighted on the Si2p spectra with a component at $100.6 \mathrm{eV}$ [51] 


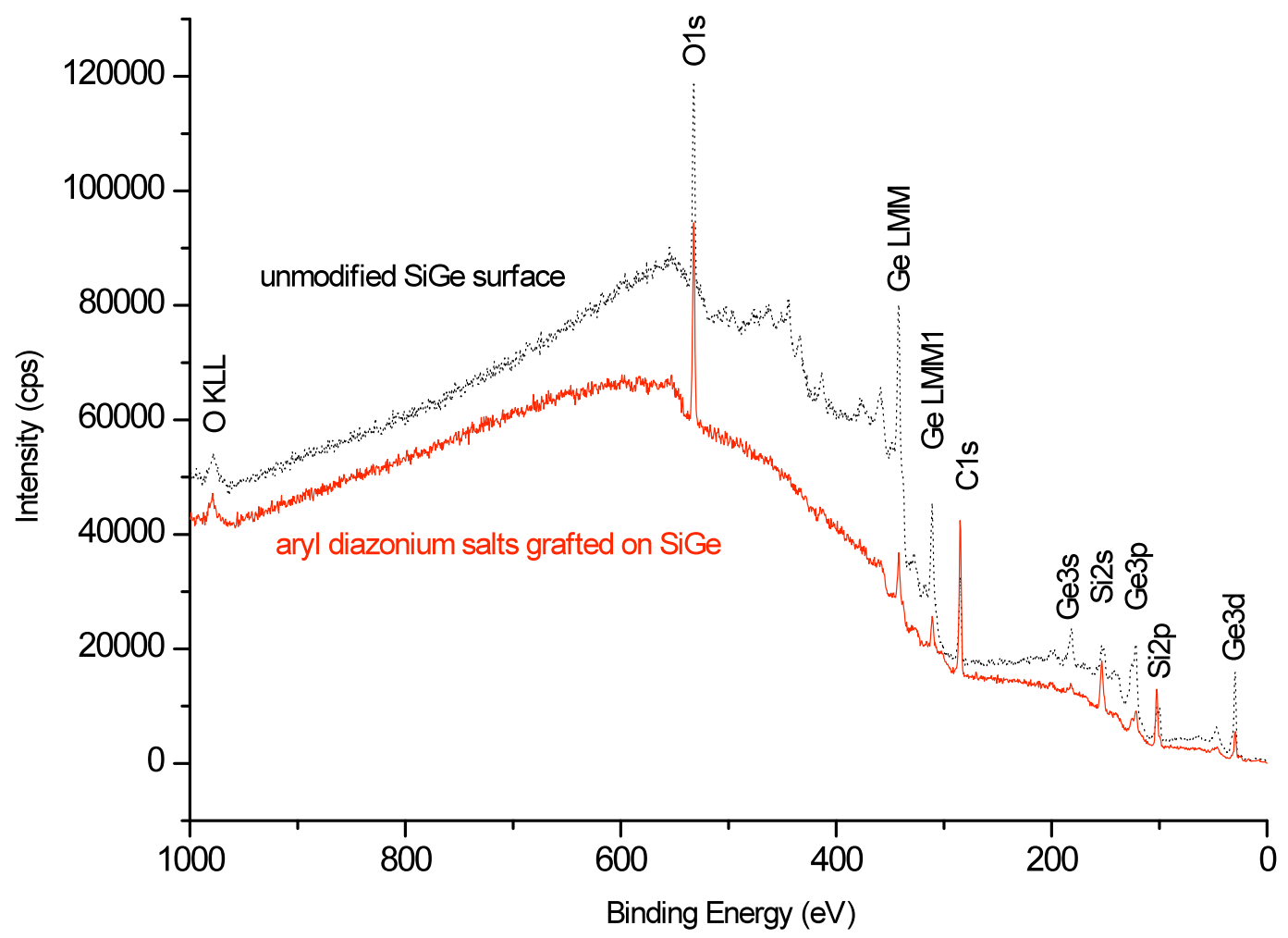

Figure 2. Survey scans of SiGe (dotted line) and substituted phenyl groups grafted on SiGe (continuous line) with main peak assignment.

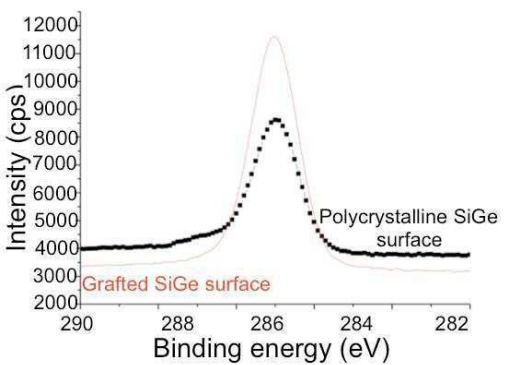

(a)

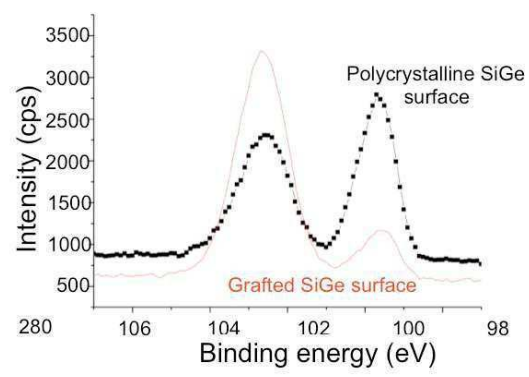

(b)

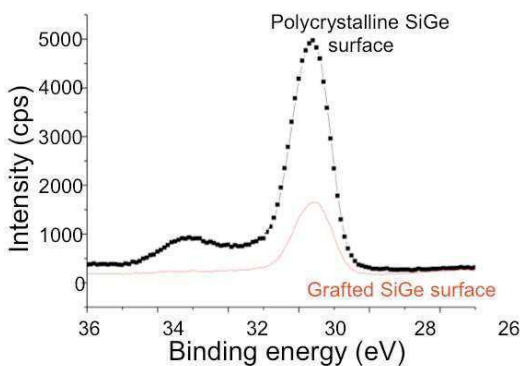

(c)

Figure 3. (a) C1s XPS spectrum of a grafted SiGe surface as compared to a reference sample of polycrystalline SiGe surface. Details of the Si2p (b) and Ge3d (c) core level spectra of the same sample. 


\begin{tabular}{|c|c|c|c|}
\hline $\begin{array}{l}\text { Element } \\
\text { (Photo electron core level) }\end{array}$ & Assignment & $\begin{array}{l}\text { Binding Energy } \\
(\mathrm{eV})\end{array}$ & References \\
\hline \multirow[t]{5}{*}{$\mathrm{Ge}(\mathrm{Ge} 3 \mathrm{~d})$} & $\mathrm{Ge}-\mathrm{Ge}$ & 30.0 & \multirow{5}{*}[27,39,42,45,46,47,48]{} \\
\hline & $\mathrm{Ge}-\mathrm{C}$ & 35.6 & \\
\hline & $\mathrm{Ge}-\mathrm{H}-\mathrm{C}$ & 36.4 & \\
\hline & $\mathrm{GeO}_{\mathrm{x}} \mathrm{C}_{\mathrm{y}}$ & 32.1 & \\
\hline & $\mathrm{Ge}-\mathrm{O}\left(\mathrm{Ge}^{+1}\right)$ & Shift of $0.85 \mathrm{eV}$ & \\
\hline \multirow[t]{7}{*}{$\mathrm{C}(\mathrm{C} 1 \mathrm{~s})$} & $\mathrm{C}-\mathrm{Si}$ & $283.4-284.6$ & \multirow{7}{*}{$\begin{array}{l}{[12,27,42,44,49]} \\
{[8,40,50,51]} \\
{[37,52]}\end{array}$} \\
\hline & $\mathrm{C}-\mathrm{C} / \mathrm{C}-\mathrm{H}$ aromatic & 284.5 & \\
\hline & $\mathrm{C}-\mathrm{C} / \mathrm{C}-\mathrm{H}$ aliphatic & $284.8-285.1$ & \\
\hline & $\mathrm{CH}_{2}-\mathrm{COOH}(\beta-\mathrm{COOH})$ & $285.1-285.6$ & \\
\hline & $\mathrm{C}-\mathrm{O}$ & $286-286.8$ & \\
\hline & $\mathrm{O}=\mathrm{C}-\mathrm{O}$ & $287.0-288.0$ & \\
\hline & $-\mathrm{COOH}$ & $289.0-290.5$ & \\
\hline \multirow[t]{5}{*}{$\mathrm{Si}(\mathrm{Si} 2 \mathrm{p})$} & $\mathrm{Si}-\mathrm{Si}$ & $99-99.6$ & \multirow{5}{*}[35,39,46]{} \\
\hline & $\mathrm{Si}-\mathrm{C}$ & $100.5-101$ & \\
\hline & $\mathrm{SiO}_{\mathrm{x}} \mathrm{C}_{\mathrm{y}}$ & $101.3-102.4$ & \\
\hline & $\mathrm{SiO}_{\mathrm{x}}$ & 102.7 & \\
\hline & $\mathrm{SiO}_{2}$ & $103.5-103.7$ & \\
\hline \multirow[t]{6}{*}{$\mathrm{O}(\mathrm{O} 1 \mathrm{~s})$} & $\mathrm{C}=\mathrm{O}$ & $531.0-532.2$ & \multirow{6}{*}[42,44,46,52,53]{} \\
\hline & $\mathrm{Si}-\mathrm{O}-\mathrm{Si}$ & $531.4-531.7$ & \\
\hline & $\mathrm{O}-\mathrm{H}$ & $530.8-532.0$ & \\
\hline & $\mathrm{GeO}_{2}$ & 531.6 & \\
\hline & $\mathrm{SiO}_{2}$ & 532.3 & \\
\hline & $\mathrm{C}-\mathrm{O}-\mathrm{C}$ & 532.3 & \\
\hline
\end{tabular}

Table 4. Summarizes the different binding energies and chemical bond assignments used in the decomposition spectra. 


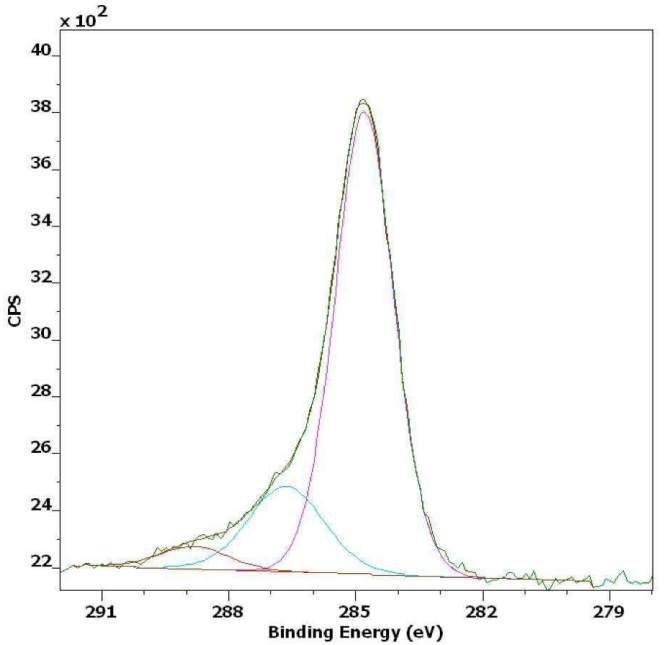

(a)

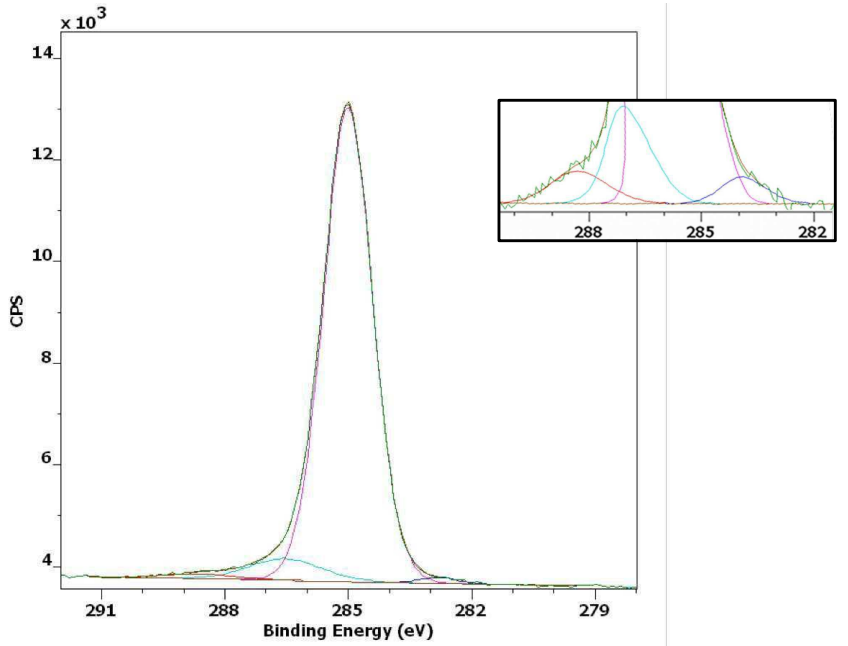

(b)

Figure 4. Deconvolution of C1s core level spectra obtained with AlK $\alpha$ excitation. (a) C1s spectra of the polycrystalline SiGe surface and (b) C1s spectra of the surface with an aryl diazonium salts-modified layer. A fit deconvolution into four different carbon binding states is shown.

in the deconvolution (Figure 5a). No carbide type bonds Ge-C is observed in the deconvolution of the Ge $3 \mathrm{~d}$ spectrum. However, a new peak is highlighted at $32.2 \mathrm{eV}$ which can be attributed to $\mathrm{GeO}_{\mathrm{x}} \mathrm{C}_{\mathrm{y}}$ (Figure $5 \mathrm{~b}$ ).

It seems that the surface roughness favors grafting. Diazonium salts seem to be grafted more easily on polySi than Ge substrate. A similar study is made of polycrystalline Ge. The peak Ge can be decomposed into three features: the $\mathrm{Ge} 3 \mathrm{~d}$ doublet located at 29.4 and $29.9 \mathrm{eV}$ assigned to $\mathrm{Ge}-\mathrm{Ge}$ bonds, one at $31.7 \mathrm{eV}$ assigned to $\mathrm{Ge}-\mathrm{H}$ or $\mathrm{GeO}$ bonds and the last at $33.2 \mathrm{eV}$ assigned to $\mathrm{Ge}-\mathrm{O}$ bonds. After grafting, a new component appears at $32.2 \mathrm{eV}$ which can be attributed to the $\mathrm{GeO}_{\mathrm{x}} \mathrm{C}_{\mathrm{y}}$ bonds. The observed oxygen peak can be attributed to a partial deoxidation by $\mathrm{HF}$ solution or to a reoxidation of the part of the substrate which have not reacted with the aryl diazonium salts [28, 47].

In addition to identifying elements present, XPS allows one to perform quantitative analysis. The surface composition was determined using the manufacturer's sensitivity factors. The fractional concentration of a particular element A (\% A) was computed using:

$$
\% A=(I A / S A) * 100 \frac{\sum I n}{S n}
$$

where $I n$ and $S n$ are the integrated peak areas and the sensitivity factors, respectively. The formula is correct for homogeneous samples only and was used for rapid comparison of different samples. Information on elemental composition of the samples are summarized in Table 5. The presence of Si signal on Ge surfaces could be due to the thin $\mathrm{Si}$ adhesion layer and to the afterglow of the deposition reactor.

Considering that a homogeneous layer is formed, the attenuation of the Si2p photoelectron signal through the top layer yields insights into the molecular films thickness $(\mathrm{z})$. This thickness $(\mathrm{nm})$ could be estimated by the standard overlayer model [35].

$$
I_{s}=I_{s}^{\infty} \exp \left(-z / \lambda_{s} \cdot \cos a\right)=I_{s}^{\infty} \exp \left(-z / \lambda_{s} \cdot \sin \theta\right)
$$

Where $I s$ is the intensity of the attenuated $\mathrm{Si} 2 \mathrm{p}$ signal, $I_{s}^{\infty}$ is the Si2p signal coming from the Si sample without any overlayer, $\lambda_{s}(\mathrm{~nm})$ is the photoelectron mean free path of the substrate-specific photoelectrons in the analyzed material, $a$ is the photoelectron emission angle with respect to the detector axis and $\theta$ is the analysis takeoff angle relative to the surface. 


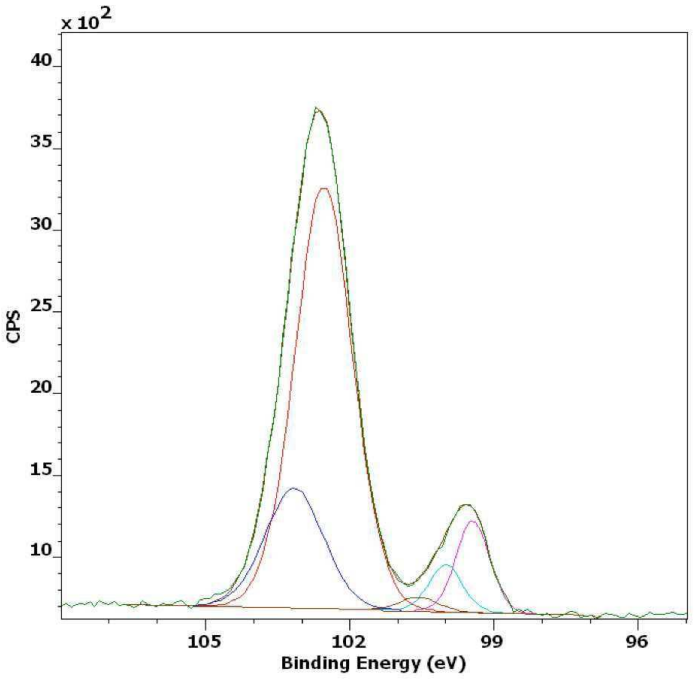

(a)

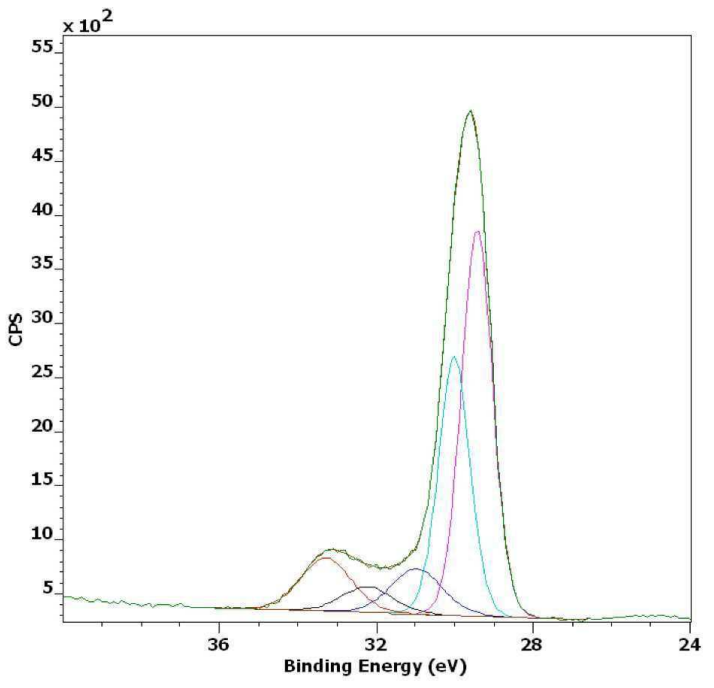

(b)

Figure 5. XPS spectra of an aryl diazonium salts layer grafted on polycrystalline SiGe. (a) Deconvolution of Si2p spectra and (b) Ge3d spectra.

\begin{tabular}{lllll}
\hline Substrates & & $\mathrm{C}($ at\%) & Si (at\%) & Ge (at\%) \\
\hline Silicon (100) & substrate & 42.8 & 35.1 & \\
& modified surface & 44.8 & 29.0 & \\
\hline Heavily P-type polycrystalline SiGe & substrate & 34.5 & 18.7 & 17.8 \\
& modified surface & 50.9 & 19.8 & 5.6 \\
\hline Heavily P-type polycrystalline Ge & substrate & 34.0 & 3.1 & 33.9 \\
& modified surface & 42.7 & 16.0 & 13.7 \\
\hline
\end{tabular}

Table 5. Results of XPS elemental analysis in at\%. 


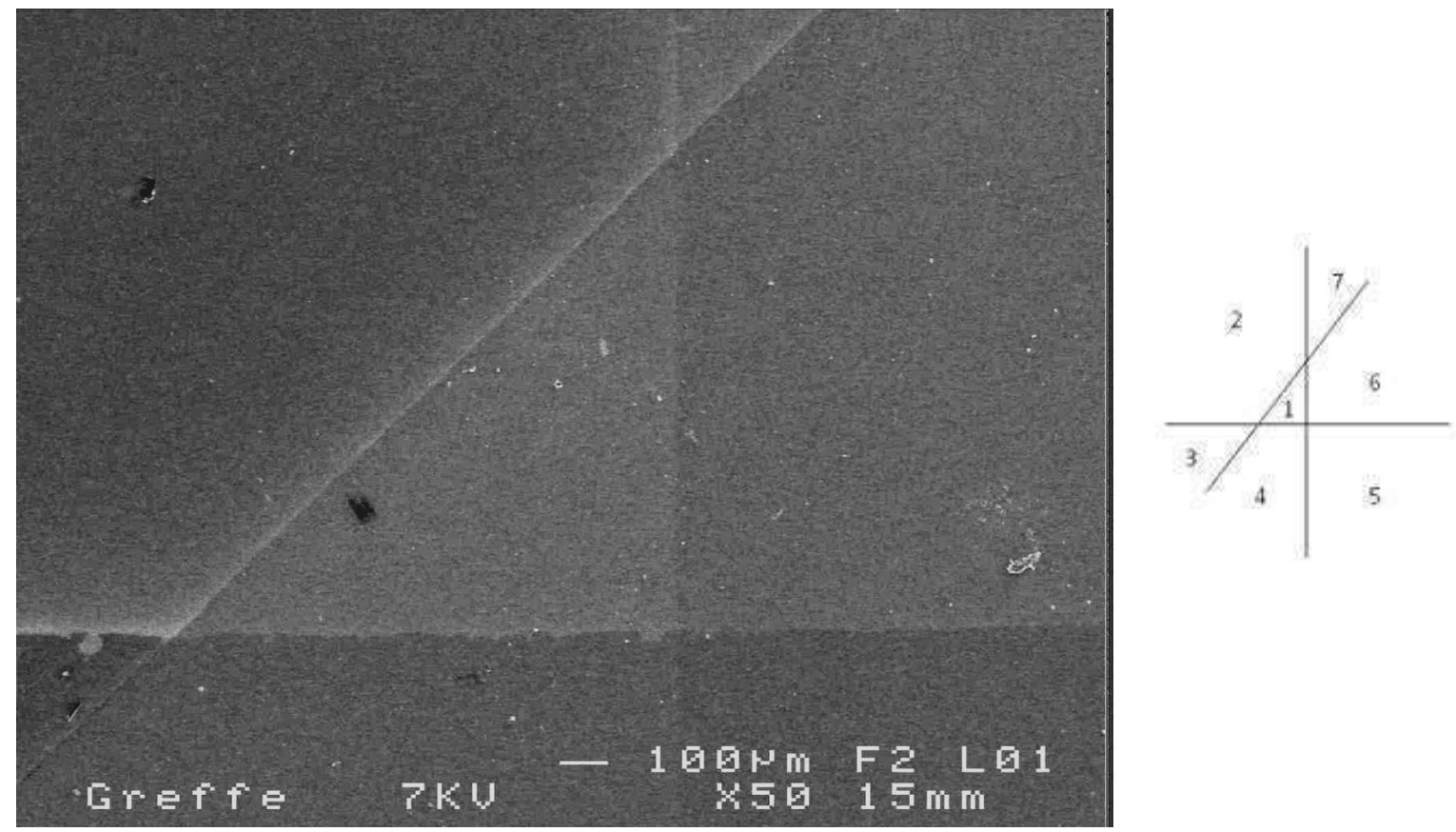

\begin{tabular}{lccclclc}
\hline Zone & 1 & 2 & 3 & 4 & 5 & 6 & 7 \\
\hline Power $(\mathrm{W})$ & 30 & - & 100 & $100+30$ & $100+30+30$ & $30+30$ & 30 \\
Time $(\mathrm{min})$ & 10 & - & 10 & $10+10$ & $10+10+10$ & $10+10$ & 10 \\
\hline
\end{tabular}

Figure 6. SEM image of different etching conditions on SiGe grafted surface and conditions for plasma $\mathrm{O}_{2}$ on SiGe grafted surface by zone.

The electron attenuation length for Si was obtained from Henry de Villeneuve et al. [36], where the $\lambda_{s}$ value was equal to $4 \pm 0.5 \mathrm{~nm}[37,38]$. The thickness of the grafted layer was calculated for the different substrates (Table 3 ).

For each type of sample, we used the attenuation of the substrate signal to estimate the grafted layer thickness. This means that for different samples ( $\mathrm{Si}, \mathrm{SiGe}$ and $\mathrm{Ge}$ ), we analyzed the response of the unmodified substrate and of the substrate with grafted layer. So, we used the attenuation of Si2p (in Si-Si component at $99.6 \mathrm{eV}$ ) and Ge3d photoelectron signal.

\subsection{Thickness Study}

\subsubsection{Remove of the organic layer by plasma}

To confirm the thickness estimations by XPS, the grafted surfaces were post-exposed to an oxygen plasma to etch the organic layer added by the grafting protocol and to measure its thickness by AFM. This etching technique is well-known in microelectronics to remove organic layers without damaging the substrate [54, 55, 56, 57]. Before measurements, SEM images were realized on functionalized SiGe surfaces (Figure 6) to find the best conditions to remove all the organic layer. Indeed, SEM image contrast differs according to the thickness of the organic layer on the silicon semiconductor.

At the scale of SEM, the grafted layer appears homogenous and uniform on all the SiGe surface. After the first 100W plasma (zone 3), the surface appearance of the zones 3, 4 and 5 seems to be similar. Thus, an increase in plasma etching time does not significantly modify the surfaces. This indicates that the organic layer is totally etched after 10 min of $100 \mathrm{~W}$ plasma treatment. After a $30 \mathrm{~W}$ plasma during $10+10 \mathrm{~min}$ (zone 6 ), the grafted layer is still visible. SEM images acquired at 50000x magnification show that the space between grains boundaries increases corresponding to a drop of the covering, but not as zone 3 (Figure 7). 


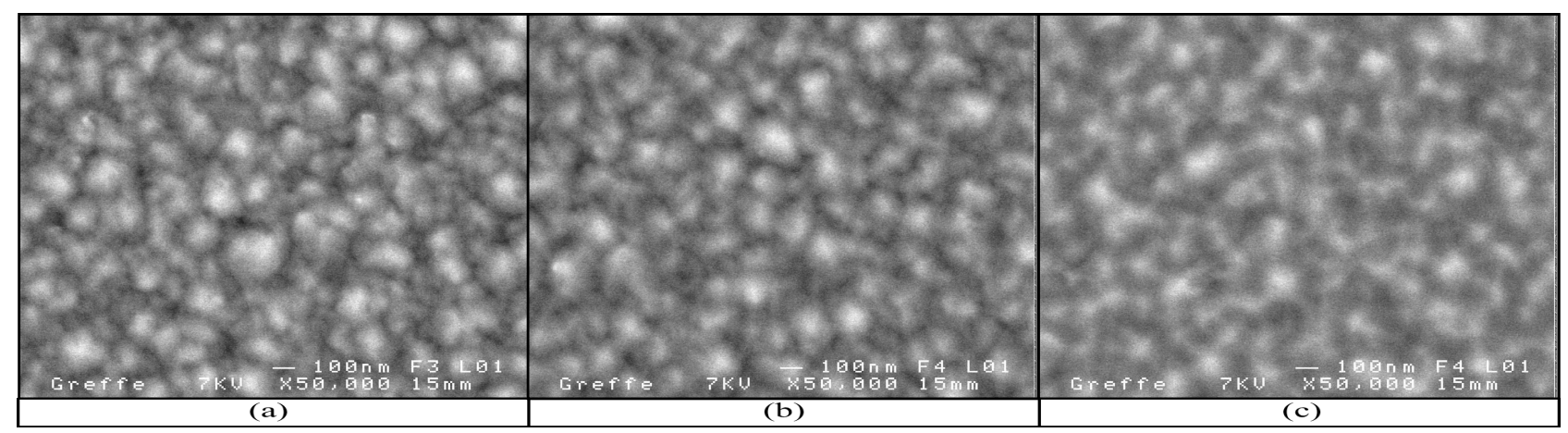

Figure 7. SEM images of SiGe grafted surface: (a) before etching in zone 2, (b) after $10+10 \min 30 \mathrm{~W} \mathrm{O}_{2}$ plasma etching in zone 6 and (c) after 10 $\min 100 \mathrm{~W} \mathrm{O}_{2}$ plasma etching in zone 3 .

\begin{tabular}{lc}
\hline Substrates & Step measurement \\
\hline Silicon (100) & $1.9 \mathrm{~nm}^{b} \pm 0.2$ \\
Heavily P-type polycrystalline SiGe & $3.5 \mathrm{~nm}^{c} \pm 0.4$ \\
Heavily P-type polycrystalline Ge & $2.8 \mathrm{~nm}^{c} \pm 0.3$ \\
\hline${ }^{a}$ uncertainties are based on 10 reproducibility measurements, ${ }^{b} \mathrm{AFM} \mathrm{and}^{c}$ profilometer &
\end{tabular}

Table 6. Thickness of the grafted layer deduced from the step measurement obtained by plasma etching.

Non-grafted surfaces of $\mathrm{Si}$ and $\mathrm{SiGe}$ were exposed to an oxygen plasma (20 sccm, $100 \mathrm{~W}$ during $10 \mathrm{~min}$ ). The $\mathrm{O}_{2}$ plasma treatment did not etch the substrate surface. Indeed, the Si2p doublet decomposition results, by XPS, show no broadening of FWHM Si2p3/2.

Thus a $100 \mathrm{~W}$ plasma treatment was used in the following experiments to remove the organic layers.

\subsubsection{Thickness measurements}

Imaging tools like AFM and profilometer can be used to produce high-resolution topographic images. In order to measure the thickness of the functionalization layer, the film is totally etched by a $100 \mathrm{~W}$ oxygen plasma. A part of the sample was mechanically masked with a cleaved silicon wafer. In AFM, we clearly observed a step corresponding to the transition between the grafting layer and the cleaned substrate (Figure 8) .

The thickness measurement of the step on the SiGe and Ge is difficult to realize by AFM due to the roughness of the surface. However, it can be easily estimated on the Si substrate as observed in Figure 9. As the roughness is to high to allow the determination of the thickness by AFM, for Ge-composed surfaces we tried to do the measurement with a profilometer. This technique can be used here because the etching was performed on a large surface area. As observed in Figure 10, the step was well defined and easily measured.

All the thicknesses measured by AFM or profilometer are given in Table 6. They represent an average on ten line measurements. The long step allows to multiply the number of measurements if it is necessary.

\subsubsection{Discussion}

The effectiveness of the spontaneous grafting of diazonium salts on surfaces composed with germanium was clearly evidenced by XPS analyses with an increase of the $\mathrm{C} 1 \mathrm{~s}$ and O1s components and an attenuation of the peaks characteristic of the substrate. Since the organic layer can withstand sonication in acetonitrile and C-Si and C-Ge bonds have been clearly highlighted by XPS after grafting, covalent immobilization of the aryl compound is obvious. AFM and SEM images show the presence of homogenous layers on the surface. Thus, spontaneous grafting with diazonium salts can be achieved on SiGe and Ge surfaces. Thickness measurements indicate that the grafting process is even more efficient on Ge derivatives than on $\mathrm{Si}(100)$ surfaces. This behavior is in accordance with literature 


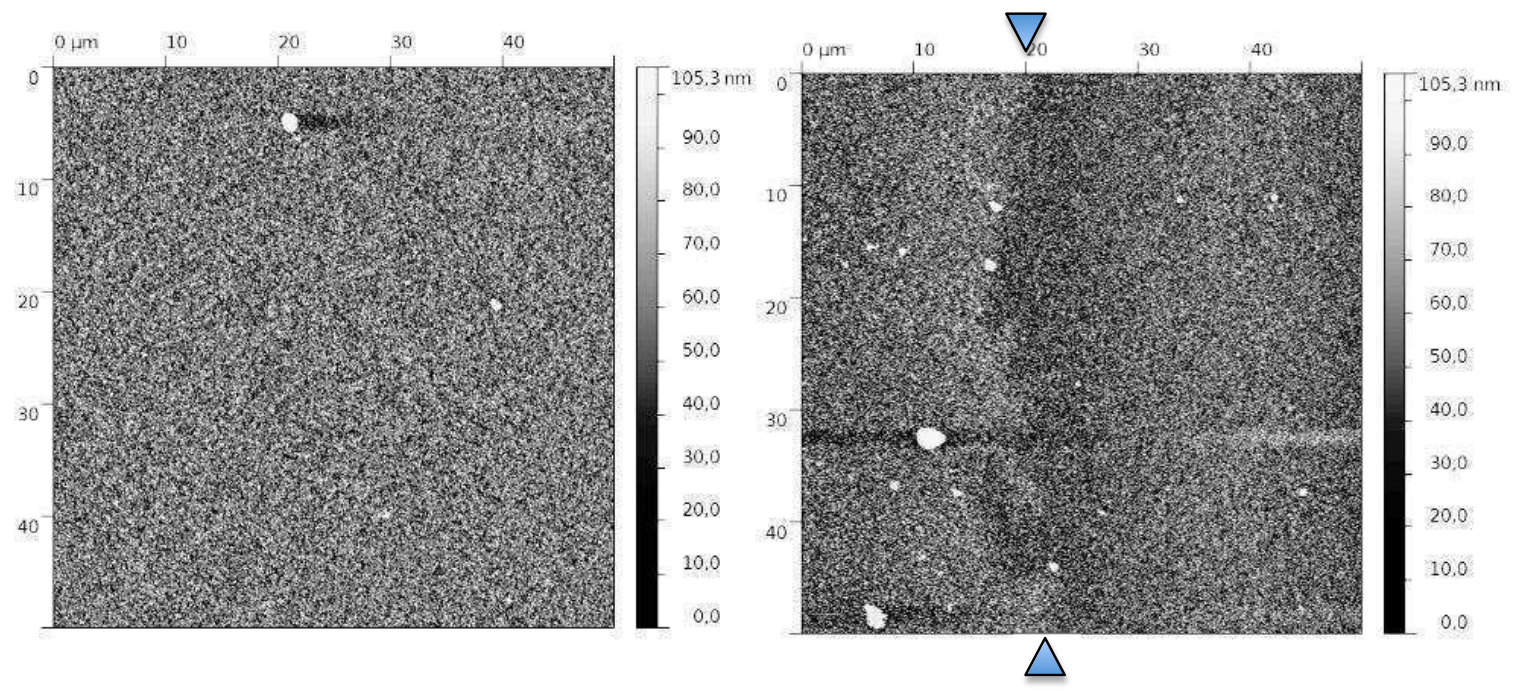

Figure 8. AFM image of SiGe grafted surface (a) and AFM image of the step (b) created after $\mathrm{O}_{2}$ plasma etching.
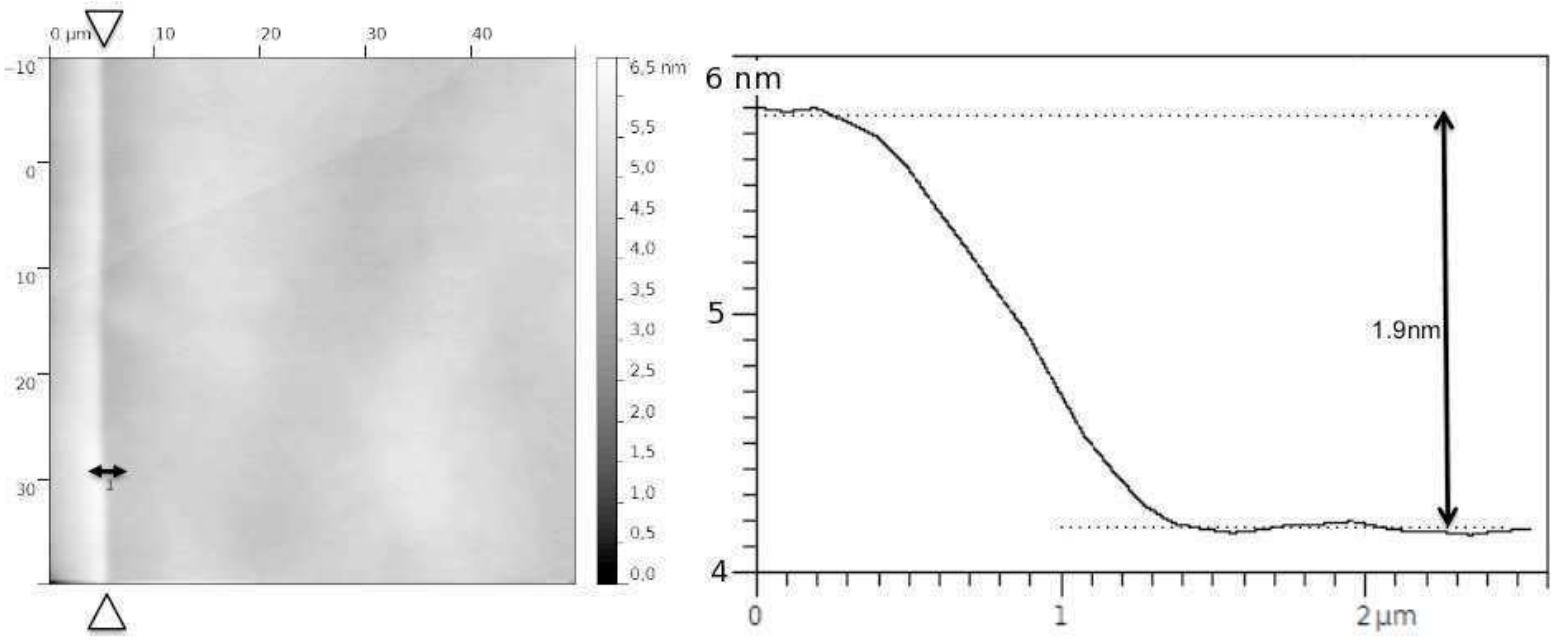

Figure 9. AFM image of Si grafted surface (before and after $\mathrm{O}_{2}$ plasma etching) and AFM step measurement of the grafted surface. 


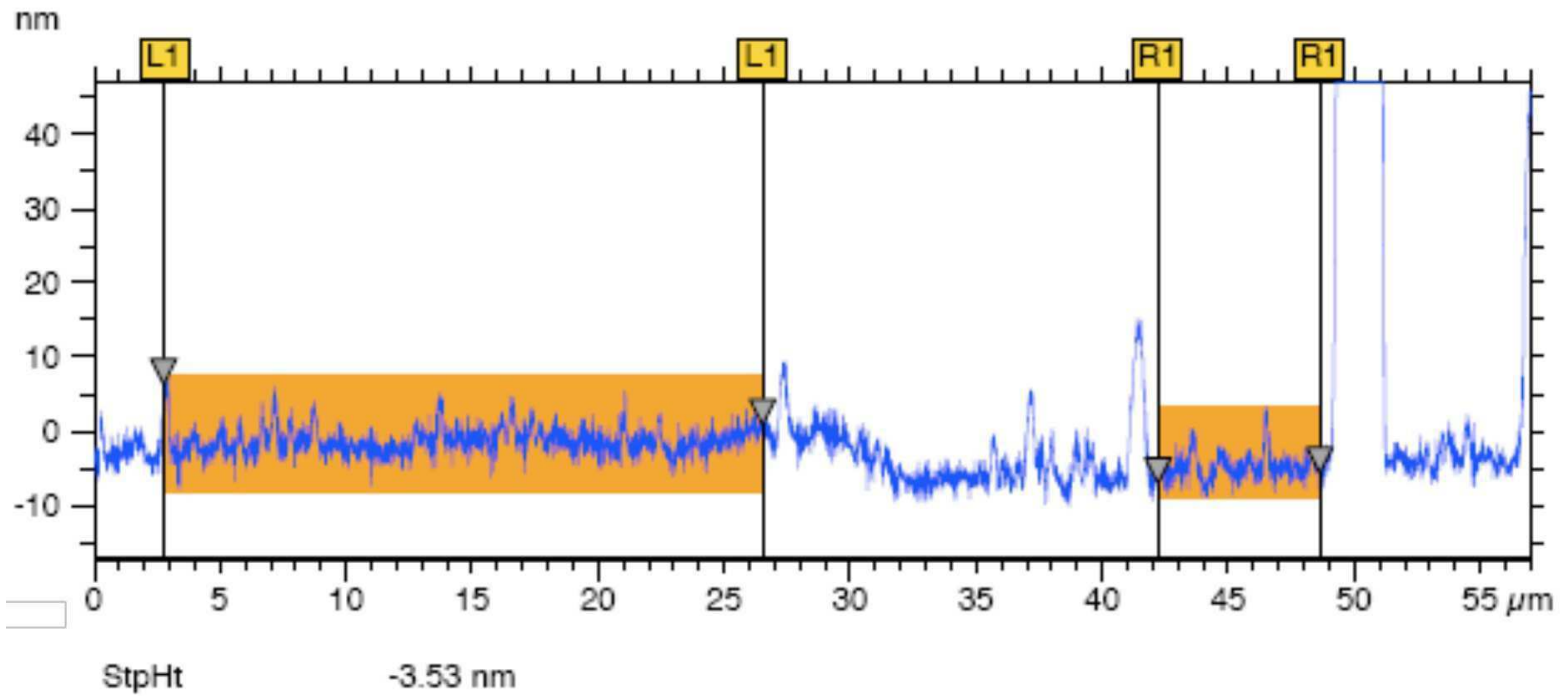

Figure 10. SiGe step measurement by profilometer.

[28] since a maximum of derivatization has been observed for only 15 min of reaction at room temperature on Ge. However, it is different than Ge nanowires that require increased temperature to be modified [27]. It is worth noting that for SiGe and Ge, XPS analyses reveal the decrease of the Ge signal after HF treatment and the presence of $\mathrm{Si}-\mathrm{C}$ and $\mathrm{Ge}-\mathrm{C}$ bonds on modified surfaces. Thus, the attachment of aryl compounds not only takes place on Ge but also on the polySi surface. Since this type of semiconductor is known to be highly reactive towards spontaneous reduction of diazonium salts [58], it can help the reaction to occur and increase the reactivity of the surface. Despite the decrease of Ge, the roughness was maintained after derivatization. It is an advantage since it should increase the amount of grafting binding sites and so amplify the electrical signal of sensors. Although this study only deals with spontaneous grafting process, it is interesting to note that all the substrates are doped and can also be used as electrodes, making possible an electrochemical grafting by cathodic reduction of diazonium salts. This would be specially interesting for applications requiring electrically addressable functionalization of surfaces [59].

An original method combining an $\mathrm{O}_{2}$ plasma etching with AFM/profilometer step measurements was used here to estimate the thickness of the organic layer. A correlation with XPS analyses was performed to check the validity of the method. The values for all the substrates were 10-30 \% lower than those estimated by XPS (Table 3). However, the proportions between the thicknesses of the three different substrates were relatively well maintained. A such difference is not surprising; indeed XPS gives a mean of the thickness on all the surface area analysis, whereas the combination of plasma and AFM/profilometer is a punctual measurement. Moreover, the values are not so far away from those of XPS, since the error was estimated to be $0.5 \mathrm{~nm}$.

AFM topography imaging is usually used to measure the step edges of organic layer, by manually scratching or by scratching the functionalized surface with the AFM tip in contact mode by applying force $[60,15]$. Thus, the AFM scratching describes intentional damage to an additional layer on a substrate. If the applied force is sufficient to remove the entire organic layer but without damaging substrate, it is possible to carve a square trench in the organic layer.

The challenge is to scratch away the functionalization, without adding the high topography features at the edge of the scratch, which are debris that has built up during the scratch and which would produce an overestimate of the thickness [14]. Interestingly, a well-controlled oxygen plasma etching does not damage semiconductors substrates, as demonstrated here by XPS: the Si2p doublet decomposition results show no broadening of FWHM Si2p3/2. Moreover, by this way, the obtained step can be as long as the studied sample, allowing an easy control of the homogeneity of the organic film by AFM or SEM imaging. Step height measurements can also be easily averaged on a large surface area of the sample. Contrary to the scratching technique, the analyze is done on a long step (more than on a $2 \times 2 \mu \mathrm{m}$ 
micrography).

For the thickness measurement approach described here, both AFM and profilometer are complementary. AFM is used to examine the surfaces with surface roughness lower than $10 \mathrm{~nm}$, whereas profilometer is more adapted to less smooth samples.

\section{Conclusion}

This report demonstrates by XPS and AFM the feasibility of a simple approach to functionalize silicon-germanium surfaces. First with XPS, the presence of covalently grafted aryl species was evidenced by analyzing Carbon, Silicon and Germanium core level. Then with AFM, the grafting was highlighted by an increase of the RMS roughness of all the functionalized substrates. Moreover, the grafted thicknesses was measured by an original technique composed of an $\mathrm{O}_{2}$ plasma etching and a step measurement by AFM or profilometer, depending on the roughness of the substrate. The etched layers can be appreciated also by SEM imaging. All the obtained results gave the same tendencies by XPS and by step measurement: the layer grafted on SiGe is thicker than on $\mathrm{Ge}$, which is also thicker than on $\mathrm{Si}$.

The depletion of the Ge thin layers during HF treatment, leading to covalent grafting on both Ge and polySi can explain the high reactivity of SiGe surfaces towards diazonium salts. Stable organic layers, allowing the addition of different functional groups required for the immobilization of chemical or biological species was thus readily achieved on SiGe. Since germanium can find applications in many areas such as fiber optics, infrared devices, polymerization catalysts, electronics and solar electric applications, such an easy and fast grafting procedure would readily find new applications. At the moment, we are currently studied the transfer of this functionalization technique on an electronic sensor composed of semiconductors.

The $\mathrm{O}_{2}$ plasma etching technique can provide rapid, nondestructive thickness measurements, by AFM and profilometer, for a wide range of semiconductors substrates. This combination of methods is expected to be particularly useful for thickness measurements of thin organic films, which cannot be evaluated readily by more traditional methods. Since the etching procedure leads to a step that can be as long as the sample, the homogeneity of the grafting process can also be easily controlled by this technique.

\section{References}

[1] Y. Guo, G. Yu, Y. Liu, Functional organic fieldeffect transistors, Adv. Mater. 22 (2010) 4427-4447.

[2] A. Spetz, S. Nakagomi, H. Wingbrant, H. Andersson, M. Salomonsson, A. Salomonsson, S. Roy, G. Wingqvist, I. Katardjiev, M. Eickhoff, K. Uvdal, K. Yakimova, New materials for chemical and biosensors, Mater. Manuf. Process. 21 (2006) $253-256$.

[3] M. Kollàr, Sensors 5 (2005) 126-138.

[4] H. Katz, Electroanal. 16 (22) (2004) 1837-1842.

[5] S. Ciampi, J. Harper, J. Gooding, Wet chemical routes to the assembly of organic monolayers on silicon surfaces via the formation of si-c bonds: surface preparation, passivation and functionalization, Chem. Soc. Rev. 39 (2010) 2158-2183.

[6] Y. Li, S. Calder, O. Yaffe, D. Cahen, H. Haick, L. Kronik, H. Zuilhof, Hybrids of organic molecules and flat, oxide-free silicon: High-density monolayers, electronic properties, and functionalization, Langmuir 28 (2012) 9920-9929.

[7] S. Onclin, R. Ravoo, D. Reinhoudt, Engineering silicon oxide surfaces using selfassembled monolayers, Angew Chem. Int. Ed. 44 (2005) $6282-6304$.

[8] D. Belanger, J. Pinson, Electrografting: a powerful method for surface modification, Chem. Soc. Rev. 40 (2011) $3995-4048$.

[9] M. M. Chehimi (Ed.), Aryl Diazonium Salts: New Coupling Agents in Polymer and Surface Science, 1st Edition, Wiley-VCH Verlag GmbH \& Co. KGaA, 2012.

[10] A. Masheter, G. Wildgoose, A. Crossley, J. Jones, R. Compton, A facile method of modifying graphite powder with aminophenyl groups in bulk quantities, J. Mater. Chem. 17 (2007) 3008-3014

[11] A. Mesnage, S. Esnouf, P. Jégou, G. Deniau, S. Palacin, Understanding the redox-induced polymer grafting process: a dual surface-solution analysis, Chem. Mater. 22 (2010) 6229-6239.

[12] B. Chen, A. Flatt, H. Jian, J. Hudson, J. Tour, Molecular grafting to silicon surfaces in air using organic triazenes as stable diazonium sources and hf as a constant hydride-passivation source, Chem. Mater. 17 (2005) 4832-4836.

[13] P. Allongue, C. Henry de Villeneuve, G. Cherouvrier, R. Cortes, M. C. Bernard, Phenyl layers on h-si (111) by electrochemical reduction of diazonium salts: monolayer versus multilayer formation, Electroanal. Chem. 550 (2003) 161-174.

[14] P. Brooksby, A. Downard, Electrochemical and atomic force microscopy study of carbon surface modification via diazonium reduction in aqueous and acetonitrile solutions, Langmuir 20 (2004) 5038-5045.

[15] F. Anariba, S. H. DuVall, R. L. McCreery, Mono- and multilayer formation by diazonium reduction on carbon surfaces monitored with atomic force microscopy "scratching", Anal. Chem. 75 (15) (2003) 3837-3844.

[16] F. Podvorica, F. Kanoufi, J. Pinson, C. Combellas, Spontaneous grafting of diazoates on metals, Electrochim. Acta 54 (2009) $2164-2170$. 
[17] Y. Leroux, H. Fei, J. M. Noel, C. Roux, P. Hapiot, Efficient covalent modification of a carbon surface: Use of a silyl protecting group to form an active monolayer, J. Am. Chem. Soc. 132 (2010) 14039-14041.

[18] S. Dauphas, A. Corlu, C. Guguen-Guillouzo, S. Ababou-Girard, O. Lavastre, F. Geneste, Covalent immobilization of antibodies on electrochemically functionalized carbon surfaces, New J. Chem. 32 (2008) 1228-1234.

[19] B. P. Corgier, A. Laurent, P. Perriat, L. J. Blum, C. A. Marquette, A versatile method for direct and covalent immobilization of dna and proteins on biochips, Angew Chem. Int. Ed. 46 (22) (2007) 4108-4110.

[20] S. E. Baker, K.-Y. Tse, E. Hindin, B. M. Nichols, T. L. Clare, , R. J. Hamers, Covalent functionalization for biomolecular recognition on vertically aligned carbon nanofibers, Chem. Mater. 17 (20) (2005) 4971-4978.

[21] G. Liu, J. J. Gooding, An interface comprising molecular wires and poly (ethylene glycol) spacer units self-assembled on carbon electrodes for studies of protein electrochemistry, Langmuir 22 (2006) 7421-7430.

[22] J. Buriak, Organometallic chemistry on silicon and germanium surfaces, Chem. Rev. 102 (5) (2002) 1272-1308.

[23] Q. Xie, S. Deng, M. Schaekers, D. Lin, M. Caymax, A. Delabie, X. Qu, Y. Jiang, D. Deduytsche, C. Detavernier, Germanium surface passivation and atomic layer deposition of high-k dielectrics-a tutorial review on ge-based mos capacitors, Semicond. Sci. Tech. 27 (2012) $1-14$.

[24] H.-J. Yang, H.-Y. Tuan, High-yield, high-throughput synthesis of germanium nanowires by metal-organic chemical vapor deposition and their functionalization and applications, J. Mater. Chem. 22 (2012) 2215-2225.

[25] G. Collins, J. D. Holmes, Chemical functionalisation of silicon and germanium nanowires, J. Mater. Chem. 21 (2011) $11052-11069$.

[26] V. C. Holmberg, M. R. Rasch, B. A. Korgel, Pegylation of carboxylic acid-functionalized germanium nanowires, Langmuir 26 (17) (2010) $14241-14246$.

[27] G. Collins, P. Fleming, C. O’Dwyer, M. Morris, J. D. Holmes, Organic functionalization of germanium nanowires using arenediazonium salts, Chem. Mater. 23 (2011) 1883-1891.

[28] X. Lefèvre, O. Segut, P. Jergou, S. Palacin, B. Jousselme, Towards organic film passivation of germanium wafers using diazonium salts: Mechanism and ambient stability, Chem. Sci. 3 (2012) 1662-1671.

[29] C. Bourdillon, M. Delamar, C. Demaille, R. Hitmi, J. Moiroux, J. Pinson, Immobilization of glucose oxidase on a carbon surface derivatized by electrochemical reduction of diazonium salts, J. Electroanal. Chem. 336 (1992) 113-123

[30] H. Zhang, R. Feng, K. Ura, Utilizing the charging effect in scanning electron microscopy, Sci. Prog. 87 (2004) $249-268$.

[31] K. Kim, Z. Akase, T. Suzuki, D. Shin do, Surface modifications for the effective dispersion of carbon nanotubes in solvents and polymers, Mater. Trans. 51 (2012) 1080-1083.

[32] J. Fulghum, Recent developments in high energy and spatial resolution analysis of polymers by xps, J. Electron Spectrosc. 100 (1999) $331-355$.

[33] G. Beamson, D. Briggs, High Resolution XPS of Organic Polymers, Wiley, 1992.

[34] J. Charlier, L. Baraton, C. Bureau, S. Palacin, Directed organic grafting on locally doped silicon substrates, Chem. Phys. Chem. 6 (2005) $70-74$.

[35] D. Briggs, M. Seah, Practical Surface Analysis by Auger and X-Ray Photoelectron Spectroscopy, Wiley, 1983.

[36] C. H. de Villeneuve, J. Pinson, M. .Bernard, P. Allongue, Electrochemical formation of close-packed phenyl layers on si (111), J. Phys. Chem. B 101 (1997) 2415-2420.

[37] X. Wallart, C. H. de Villeneuve, P. Allongue, Truly quantitative xps characterization of organic monolayers on silicon: Study of alkyl and alkoxy monolayers on h-si (111), J. Am. Chem. Soc. 127 (2005) 7871-7878.

[38] S. Cummings, J. Savchenko, T. Ren, Functionalization of flat si surfaces with inorganic compounds-towards molecular cmos hybrid devices, Coordin. Chem. Rev. 255 (2011) 1587-1602.

[39] Y. Narita, F. Hirose, M. Nagato, Y. Kinoshita, Initial oxidation of hf-acid treated sige(100) surfaces under air exposure investigated by synchrotron radiation X-ray photoelectron spectroscopy and ir absorption spectroscopy, Thin Solid Films 517 (2008) $209-212$.

[40] P. Verma, P. Maire, P. Novak, Concatenation of electrochemical grafting with chemical or electrochemical modification for preparing electrodes with specific surface functionality, Electrochim. Acta 56 (2011) 3555-3561.

[41] X. Zhang, Electrochemical and photochemical functionalization of au and si surfaces by grafting of diazonium and azide compounds, Ph.D. thesis, Humboldt-Universität zu Berlin (2011).

[42] M. Pumera, H. Iwai, Y. Miyahara, Germanium-oxide-coated carbon nanotubes, Nanotechnology 20 (2009) 425606-425611.

[43] J. Pinson, F. Podvorica, Attachment of organic layers to conductive or semiconductive surfaces by reduction of diazonium salts, Chem. Soc. Rev. 341 (2005) 429-439

[44] A. Adenier, M.-C. Bernard, M. Chehimi, E. Cabet-Deliry, B. Desbat, O. Fagebaume, J. Pinson, F. Podvorica, Covalent modification of iron surfaces by electrochemical reduction of aryldiazonium salts, J. Am. Chem. Soc. 123 (2001) 4541-4549.

[45] S. Devouge, J. Conti, A. Goldsztein, E. Gosselin, A. Brans, M. Voue, J. D. Coninck, F. Homble, E. Goormaghtigh, J. Marchand-Brynaert, Surface functionalization of germanium atr devices for use in ftir-biosensors, J. Colloid Interf. Sci. 332 (2009) $408-415$.

[46] C. Chen, J. Liu, B. Yu, D. Zhu, Studies of the thin oxide of epitaxial sige/si film by high resolution grazing angle rutherford backscattering spectrometry and channeling, Electron. Mater. Lett. 3 (2007) 63-67.

[47] T. Hanrath, B. Korgel, Chemical surface passivation of ge nanowires, J. Am. Chem. Soc. 126 (2004) 15466-15472.

[48] C. Dube, S. Kashyap, D. Dube, D. Argawal, Growth of sige alloy nanowires in a separated h-field by microwave processing, Appl. Phys. Lett. 94 (2009) 213107-213110.

[49] T. Kuila, P. Khanra, S. Bose, N. Kim, B. Ku, B. Moon, J. Lee, Preparation of water-dispersible graphene by facile surface modification of graphite oxide, Nanotechnology 22 (2011) 305710-305718.

[50] K. Boukerma, M. Chehimi, J. Pinson, C. Blomfield, X-ray photoelectron spectroscopy evidence for the covalent bond between an iron surface and aryl groups attached by the electrochemical reduction of diazonium salts, Langmuir 19 (2003) 6333-6335.

[51] N. Graf, E. Yegen, T. Gross, A. Lippitz, W. Weigel, S. Krakert, A. Terfort, W. Unger, Xps and nexafs studies of aliphatic and aromatic amine species on functionalized surfaces, Surf. Sci. 603 (2009) 2849-2860.

[52] T. Matrab, M. Save, B. Charleux, J. Pinson, E. Cabet-Deliry, A. Adenier, M. M. Chehimi, M. Delamar, Grafting densely-packed poly (n-butyl 
methacrylate) chains from an iron substrate by aryl diazonium surface-initiated atrp: Xps monitoring, Surf. Sci. 601 (2007) 2357-2366.

[53] K. Roodenko, M. Gensch, J. Rappich, K. Hinrichs, N. Esser, R. Hunger, Time-resolved synchrotron xps monitoring of irradiation-induced nitrobenzene reduction for chemical lithography, J. Phys. Chem. B 111 (2007) 7541-7549.

[54] F. D. Egitto, Plasma etching and modification of organic polymers, Pure \& Appl. Chem. 62 (9) (1990) 1699-1708

[55] A. Flounders, D. Brandon, A. Bates, Patterning of immobilized antibody layers via photolithography and oxygen plasma exposure, Biosens. Bioelectron. 12 (6) (1997) 447-456.

[56] S. Steudel, K. Myny, S. D. Vusser, J. Genoe, P. Heremans, Patterning of organic thin film transistors by oxygen plasma etch, Applied Physics Letters 89 (2006) 183503-183506.

[57] E. Meng, P. Li, Y. Tai, Plasma removal of parylene c, J. of Micromech. Microeng. 18 (2008) 13pp.

[58] J. Charlier, E. Clolus, C. Bureau, S. Palacin, Selectivity of organic grafting as a function of the nature of semiconducting substrates, J. Electroanal. Chem. 625 (1) (2009) 97-100.

[59] W. Yang, S. E. Baker, J. E. Butler, C.-S. Lee, J. N. J. Russell, L. Shang, B. Sun, R. J. Hamers, Electrically addressable biomolecular functionalization of conductive nanocrystalline diamond thin films, Chem. Mater. 17 (2005) 938-940.

[60] R. W. Carpick, M. Salmeron, Scratching the surface: Fundamental investigations of tribology with atomic force microscopy, Chem. Rev. 97 (1997) 1163-1194. 